\title{
The Advantages of Using Vascular Dilators in Angioaccess Surgery
}

\author{
Branko Fila \\ Department of Vascular Surgery, University Hospital Dubrava, Zagreb, Croatia
}

\author{
Keywords \\ End-stage renal disease - Arteriovenous fistula . \\ Hemodialysis - Operative technique · Vascular probe . \\ Quality improvement
}

\begin{abstract}
The creation of a functional angioaccess is the cornerstone in treatment of chronic hemodialysis patients. The aim of this article is to review the use of vascular probes as a simple and cheap tool that could help surgeons in preparation of vessels and with creation of an anastomosis. Autogenous arteriovenous fistula is the best angioaccess available but is hampered by its relatively high non-maturation rate. Guidelines recommend preoperative duplex ultrasonography (USG) and use of vessels with a diameter that is able to maintain sufficient flow and fistula maturation to avoid unsuccessful attempts. Despite recommendations, preoperative duplex USG is not performed in many centers. In such circumstances, the use of vascular probes could help surgeons to create a fistula with a high chance of successful maturation. Vessel probes and dilators could be used to assess vessel diameter and patency, the ability to dilate and resolve a spasm, to stop retrograde blood flow in the vein (to avoid the use of vascular clamps), to avoid torsion of vein, to open and check vessel lumen with each stitch (to avoid using the forceps and possible wall injury), for tightening of continuous suture over the probe (to avoid excessive tightening and possible anastomotic stenosis). To my knowledge, this is the first review article which summaries the experience of using
\end{abstract}

vascular dilators in angioaccess surgery. This information can be very helpful especially when there is the lack of valid preoperative USG of the vessels.

(c) 2020 S. Karger AG, Basel

\section{Introduction}

Worldwide, the prevalence of chronic kidney disease and end-stage renal disease (ESRD) has been increasing in the last decades to an epidemic proportion [1]. In the United States, the number of patients treated with chronic intermittent hemodialysis (HD) rose from 5,000 in 1972 to 380,000 in 2008 [2, 3]. According to the data published by the United States Renal Data System at the end of 2014 , there were 678,383 prevalent ESRD patients, $63.1 \%$ of all prevalent ESRD patients were receiving HD therapy, $6.9 \%$ were being treated with peritoneal dialysis, and $29.6 \%$ had a functioning kidney transplant [4]. Globally, chronic HD is the most utilized modality of renal replacement therapy (RRT), namely, in $>75 \%$ of ESRD patients. In Europe, 592,779 prevalent patients were receiving RRT on December 31, 2017. The main RRT therapy was $\mathrm{HD}$, in $57 \%$ of patients, while peritoneal dialysis was used in $5 \%$ of patients and $37 \%$ had a functional kidney transplant [5]. Functional and durable vascular access (VA) for HD is a prerequisite for successful chronic HD treatment. Complications related to VA dysfunction represent a major cause of morbidity and hospitalization among HD patients worldwide [6-8]. There are 3 mo- karger@karger.com

(c) 2020 S. Karger AG, Basel

www.karger.com/bpu

Karger!
Branko Fila, $\mathrm{PhD}$

Department of Vascular Surgery

University Hospital Dubrava

Avenija Gojka Šuška 6, HR-10000 Zagreb (Croatia)

E-Mail bfila1964@gmail.com 
Table 1. The use of vascular probes and dilators in angioaccess surgery - review of the literature

Author(s), reference and year The purpose of vascular probes and dilators use of publication

Wang et al. [18], 2008

Exploration of arterial and vein patency and diameters. The vein was considered adequate for creation of an AVF if they could insert a $3 \mathrm{~mm}$-diameter garret dilator $10 \mathrm{~cm}$ proximally, followed by insertion of an umbilical catheter $30 \mathrm{~cm}$ proximally. The same procedure was done for the radial artery.

\begin{tabular}{ll}
\hline Tordoir et al. [15], 2003 & After arteriotomy, vessel diameters were measured with coronary probes. \\
\hline Jennings [16], 2006 & Disruption of the initial venous valve to maintain distal forearm (retrograde) flow. \\
\hline Spergel et al. [17], 2007 & Disruption of venous valves to permit retrograde flow in reverse-flow AVFs. \\
\hline Biuckians et al. [20], 2008 & $\begin{array}{l}\text { Assessment of venous anatomy by passing dilator proximally via a venotomy. The explored } \\
\text { vein was not used if they could not comfortably introduce a } 3 \text { mm dilator. }\end{array}$ \\
\hline Angle and Chandra [21], 2005 & $\begin{array}{l}\text { The vein was used if it was at least } 2.5 \text { mm, as gauged by the ability to accommodate a } 2.5 \text { mm } \\
\text { dilator. }\end{array}$ \\
\hline Greenberg et al. [22], 2008 & $\begin{array}{l}\text { A series of dilators were passed into the vein to corroborate size and patency. A suitable vein } \\
\text { had to accommodate at least a } 2.5 \text { mm dilator in order to be used for an access procedure. }\end{array}$ \\
\hline Fila et al. [23], 2014 & $\begin{array}{l}\text { Steel vascular dilators were used to assess forearm venous patency and distensibility. } \\
\text { The smaller dilators were used first and then those with a 0.5 mm larger diameter. } \\
\text { Careful and forceless use of dilators was recommended. }\end{array}$ \\
\end{tabular}

AVF, arteriovenous fistula.

dalities of VA for HD: arteriovenous fistula (AVF) as the first choice, arteriovenous graft as the second and central venous catheter as the last option. The presence of a skilled and experienced surgeon is very important in achievement of better outcomes: more AVFs and durable VAs $[9,10]$. Preoperative duplex ultrasonography (USG) and vessel mapping significantly help a surgeon to choose the right site for anastomosis and creation of an access that has a good chance of becoming functional [11-13]. Guidelines recommend preoperative USG but in many centers, especially low volume ones, this is not a routine examination in the pre-surgical phase. There is no doubt that it always has to be attempted. A quality preoperative USG has to address vessel patency, diameters, and distensibility. As the best solution, the VA surgeons should be trained to perform preoperative USG because they can compare USG findings and intraoperative situations. In the lack of valid preoperative USG, the use of vascular probes could be crucial in the achievement of an optimal surgical result. There are some variations in construction of vascular dilators, but the concept of use is the same. The dilatation of the vessel should start with the smallest dilator $(0.5$ or $1 \mathrm{~mm})$ and followed by the $0.5 \mathrm{~mm}$ bigger one. It is advisable to irrigate the vein with warm heparin- ized saline before and after dilatation to avoid a spasm and only a comfortable introduction of the probe is allowed. The same dilators are used for the measurement of the vessels, dilatation or valve disruption. The main purpose of this article is to review the experience of using vascular dilators in angioaccess surgery.

\section{Methods}

Literature search was conducted to reveal the articles described the use of vascular dilators or vascular probes in angioaccess procedures for HD.

\section{Discussion}

\section{Modality of Vascular Dilators Use}

The use of mechanical vascular dilators has been well known for many years in coronary and peripheral vascular surgery Table 1 . They can be used for vessel diameter measurement, and for an easier and accurate creation of anastomosis [14]. VA surgeons also use coronary or vascular probes as a tool that helps surgeons in 
estimation of vessel diameter, dilation of vessels and interruption of venous valves. Tordoir et al. [15] reported that after arteriotomy vessel diameters were measured with coronary probes. Jennings [16] used vessel probes to disrupt the initial venous valve to maintain distal forearm (retrograde) flow after proximal radial artery AVF construction. Spergel et al. [17] also reported the use of a probe or coronary artery dilator to disrupt venous valves to permit retrograde flow with or without antegrade flow in reverse-flow AVFs. The authors recommend this kind of AVF in patients with exhausted forearm veins but a spared proximal segment of cephalic or basilic vein. After construction of an anastomosis and valve disruption, retrograde flow may cause dilation of distal veins which can be used for cannulation. Because of side to side anastomosis, in some patients antegrade and retrograde flow can be utilized for cannulation. If one direction fails, the other one can be used [17].

Wang et al. [18] described the use of Garret dilators. The dilators were used to explore arterial and vein patency and diameters. If they discovered adequate radial and ulnar pulsation at the wrist, they then surgically explored cephalic vein patency and diameter. A vein was considered adequate for creation of an AVF if they could insert a $3 \mathrm{~mm}$-diameter Garret dilator $10 \mathrm{~cm}$ proximally, followed by insertion of an umbilical catheter $30 \mathrm{~cm}$ proximally. The same procedure was done for the radial artery. They considered an internal artery diameter sufficient if they could comfortably insert $3 \mathrm{~mm}$ or greater catheter. In the case that any of these vessels did not allow insertion of at least a $3 \mathrm{~mm}$ catheter, they explored more proximal vessels. Despite the lack of preoperative vessel mapping and significant patient comorbidities, they achieved a high proportion (69\%) of AVF attempted locally [18]. This proportion was $64 \%$ in the study of Allon et al. [19] when venous mapping was routinely performed preoperatively. Biuckians et al. [20] also reported re-assessment of venous anatomy by passing dilator proximally via a venotomy. The explored vein was not used if they could not comfortably introduce a $3 \mathrm{~mm}$ dilator. Some other investigators accept a smaller diameter of the vein for creation of an AVF [21, 22]. In the absence of preoperative USG measurement of brachial vein diameter, Angle and Chandra [21] used the coronary dilators to estimate vein size. If it was at least $2.5 \mathrm{~mm}$, as gauged by the ability to accommodate a $2.5 \mathrm{~mm}$ coronary dilator, the vein was used. In the study of Greenberg et al. [22] USG mapping of the vessels was a fundamental component in determining the suitability of the superficial veins for ac-

Vascular Probes in Angioaccess Surgery cess surgery. In the lack of adequate superficial veins, autogenous brachial vein-brachial artery anastomosis was created. A series of dilators were passed into the vein to corroborate size and patency. A suitable vein had to accommodate at least a $2.5 \mathrm{~mm}$ dilator in order to be used for an access procedure [22]. In one prospective study, steel vascular dilators were used to assess forearm venous patency and distensibility [23]. Multivariate logistic regression analysis revealed that vein diameter after intraoperative dilation was a stronger predictor of successful AVF creation in comparison to the vein diameter before dilation. The authors concluded that venous distensibility is more important than venous diameter itself. It was also underlined that the introduction of vascular dilators should not be crude. Only comfortable probe insertion is allowed. Smaller dilators should be used first, and the vein has to be irrigated with warm heparinized saline before and after dilation to avoid a spasm. Despite missing preoperative USG, the proportion of functional fistulas was $70 \%$ in that study. One of the conclusions was that vascular dilators could be a very helpful tool in the estimation of vessel's size and venous distensibility, which is especially important in the absence of preoperative USG [23].

No-Touch Surgical Technique Using Vascular Dilators

A common complication after AVF creation is juxtaanastomotic stenosis, which may cause insufficient blood flow and an inadequate HD. Neointimal hyperplasia (NIH) is usually the culprit lesion at this point. The trigger for the development of NIH could be vascular injury to the endothelium and media that occurs during surgery [24]. No-touch surgical technique is recommended $[25,26]$. To avoid the use of vascular clamps in such tiny veins and possible wall injury, vascular probes may be used. The introduction of a probe stops retrograde blood flow and also allows an easier visualization of vein lumen. In some circumstances, it enables the creation of an anastomosis without using the forceps, which can also cause vein wall injury. In these small caliber vessels, it is of great importance to avoid stenosis at the anastomosis point. According to Poiseuille's law, blood flow is proportional to the vessel radius to the fourth power. Guidelines and many articles stressed the importance of the diameter of vessels, but blood flow could be restricted on the anastomosis site in case of a stenosis caused by stitches. This could be avoided by using a vascular probe inserted in the lumen of a vessel for accurate stitches placing. Before completion of an anastomosis, the vascular probe or dilator could be inserted in the 
Table 2. The main advantages of using vascular dilators in angioaccess surgery

1. Assessment of vessel diameter and patency

2. Assessment of the vessel's ability to dilate and resolve a spasm

3. Stopping retrograde blood flow in the vein (there is no need for use of vascular clamps which may cause intimal injury)

4. Avoidance of vein torsion

5. Opening and checking the vessel's lumen with each stitch (to avoid using the forceps and possible wall injury)

6. Tightening of continuous suture over the probe (to avoid excessive tightening and possible anastomotic stenosis)

"heel" of anastomosis to gently dilate this area, which resolves possible overstraining of the continuous suture and possible stenosis [27]. Only a few authors mentioned the important role of anastomotic diameter and the possibility that early failures after surgery are often a result of technical problems with the anastomosis. Davidson et al. [28] set the anastomosis luminal diameter of at least $2.5 \mathrm{~mm}$ as one of the minimal vascular requirements for a successful AVF. In one study anastomotic diameter of $<3.5 \mathrm{~mm}$ was associated with fistula failure within 6 months after creation [29]. Hasson et al. [30] have shown that anastomotic diameter is lower with the continuous suture compared to anastomoses using an interrupted technique.

\section{Simplicity of Vascular Dilators Use}

$A$ vein used for VA should be investigated before the anastomosis construction. Clinical inspection and palpation, preoperative USG imaging, preoperative plethysmography intraoperative venography or angioscopy, irrigation of heparinized saline, exploration and dilation with vascular probes and intraoperative angioplasty are procedures that may help surgeons to estimate vein patency and distensibility. Among these procedures, the use of vascular probes and dilators seems to be the simplest technique to assess venous characteristics. A surgeon does not require special education and experience to use vascular dilators; they could be used repeatedly and this technique is easy to apply worldwide.

\section{Safety and Complications of Using Vascular Dilators}

In recent years, intraoperative angioplasty of the vein has been described. The idea of this procedure is to dilate small sized veins to allow more distal AVF and to increase the maturation rate $[31,32]$. Early results of intraoperative balloon angioplasty are promising but there are concerns about long-term results. Overdistension is unavoidable during this procedure, which may cause intimal injury and consequently NIH. Because of uncontrolled vein distension the use of a Fogarty catheter is also not recommended. In comparison with uncontrollable distension with angioplasty balloons or a Fogarty catheter, dilation with vascular dilators is graduated. Smaller dilators are used first, and then those with a $0.5 \mathrm{~mm}$ larger diameter. In case of an uncomfortable introduction of dilators, the procedure should be interrupted. This is the main advantage of the use of vascular dilators over angioplasty balloons. The second advantage is the safety of vascular dilator use. Careful and forceless use of dilators prevents injury of the vein wall. In one study, vein dilation with steel vessel probes was performed in 93 patients and no ruptures were recorded [19]. In contrast, $15 \%$ of vein rupture occurred when the juxta-anastomotic vein and the feeding artery were dilated with 6 and $4 \mathrm{~mm}$ balloons respectively [33]. The main advantages of using vascular dilators are presented in Table 2 .

\section{Conclusion}

The creation of a functional VA is a cornerstone in treatment of patients who rely on chronic HD. It is extremely important to avoid unsuccessful attempts because a delay in creating functional angioaccess may cause prolonged central venous catheter dependence with serious complications and even the death of a patient. Preoperative USG and operative technique are the most important factors affecting success. Preoperative USG has to be mandatory because it significantly helps the surgeon to choose the right strategy. A VA surgeon has to be experienced in various operative techniques because the intraoperative situation dictates the final solution. The use of vascular dilators may help the surgeon to estimate vessel diameter, patency and distensibility. This information is especially important in the lack of valid preoperative USG, and may be crucial in the creation of a functional VA for HD in the first attempt.

\section{Acknowledgment}

Special thanks to Filip Fila for proofreading. 


\section{Statement of Ethics}

Not applicable - this is a review article.

\section{Disclosure Statement}

The author has no conflict of interest to disclose.

\section{Funding Sources}

There are no funding sources to declare.

\section{Author Contributions}

B.F. is responsible for the entire content of manuscript.

\section{References}

1 Couser WG, Remuzzi G, Mendis S, Tonelli M. The contribution of chronic kidney disease to the global burden of major noncommunicable diseases. Kidney Int. 2011 Dec;80(12): 1258-70.

2 Roberts SD, Maxwell DR, Gross TL. Cost-effective care of end-stage renal disease: a billion dollar question. Ann Intern Med. 1980 Feb;92(2 Pt 1):243-8.

3 Collins AJ, Foley RN, Herzog C, Chavers B, Gilbertson D, Ishani A, et al. US Renal Data System 2010 Annual Data Report. Am J Kidney Dis. 2011 Jan;57(1 Suppl 1):A8, e1-526.

4 United States Renal Data System. 2016 USRDS annual data report: Epidemiology of Kidney Disease in the United States. National Institutes of Health, National Institute of Diabetes and Digestive and Kidney Diseases, Bethesda, MD, 2016. [Accessed Feb 10, 2019]. Available from: https://www.usrds.org/2016/ view/v2_01.aspx.

5 Registry Annual Report ER. 2017. [Accessed Jan 4, 2020. Available from: https://www.eraedta-reg.org/files/annualreports/pdf/AnnRep2017.pdf.

6 Feldman HI, Kobrin S, Wasserstein A. Hemodialysis vascular access morbidity. J Am Soc Nephrol. 1996 Apr;7(4):523-35.

7 Astor BC, Eustace JA, Powe NR, Klag MJ, Fink NE, Coresh J; CHOICE Study. Type of vascular access and survival among incident hemodialysis patients: the Choices for Healthy Outcomes in Caring for ESRD (CHOICE) Study. J Am Soc Nephrol. 2005 May;16(5):1449-55.

8 Manns B, Tonelli M, Yilmaz S, Lee H, Laupland K, Klarenbach S, et al. Establishment and maintenance of vascular access in incident hemodialysis patients: a prospective cost analysis. J Am Soc Nephrol. 2005 Jan;16(1): 201-9.

9 Choi KL, Salman L, Krishnamurthy G, Mercado C, Merrill D, Thomas I, et al. Impact of surgeon selection on access placement and survival following preoperative mapping in the "Fistula First" era. Semin Dial. 2008 JulAug;21(4):341-5.

10 He C, Charoenkul V, Kahn T, Langhoff E, Uribarri J, Sedlacek M. Impact of the surgeon on the prevalence of arteriovenous fistulas. ASAIO J. 2002 Jan-Feb;48(1):39-40.

11 Robbin ML, Gallichio $\mathrm{MH}$, Deierhoi $\mathrm{MH}$ Young CJ, Weber TM, Allon M. US vascular mapping before hemodialysis access placement. Radiology. 2000 Oct;217(1):83-8.

12 Malovrh M. Native arteriovenous fistula: preoperative evaluation. Am J Kidney Dis. 2002 Jun;39(6):1218-25.

13 Allon M, Robbin ML. Increasing arteriovenous fistulas in hemodialysis patients: problems and solutions. Kidney Int. 2002 Oct; 62(4):1109-24.

14 Grande AM. Mechanical dilator for coronary and peripheral vascular surgery. Tex Heart Inst J. 1990;17(3):234-6.

15 Tordoir JH, Rooyens P, Dammers R, van der Sande FM, de Haan M, Yo TI. Prospective evaluation of failure modes in autogenous radiocephalic wrist access for haemodialysis. Nephrol Dial Transplant. 2003 Feb;18(2): 378-83.

16 Jennings WC. Creating arteriovenous fistulas in 132 consecutive patients: exploiting the proximal radial artery arteriovenous fistula: reliable, safe, and simple forearm and upper arm hemodialysis access. Arch Surg. 2006 Jan; 141(1):27-32.

17 Spergel LM, Ravani P, Asif A, Roy-Chaudhury P, Besarab A. Autogenous arteriovenous fistula options. J Nephrol. 2007 May-Jun; 20(3):288-98.

18 Wang W, Murphy B, Yilmaz S, Tonelli M, Macrae J, Manns BJ. Comorbidities do not influence primary fistula success in incident hemodialysis patients: a prospective study. Clin J Am Soc Nephrol. 2008 Jan;3(1):78-84.

19 Allon M, Lockhart ME, Lilly RZ, Gallichio $\mathrm{MH}$, Young CJ, Barker J, et al. Effect of preoperative sonographic mapping on vascular access outcomes in hemodialysis patients. Kidney Int. 2001 Nov;60(5):2013-20.

20 Biuckians A, Scott EC, Meier GH, Panneton JM, Glickman MH. The natural history of autologous fistulas as first-time dialysis access in the KDOQI era. J Vasc Surg. 2008 Feb;47(2): 415-21.

21 Angle N, Chandra A. The two-stage brachial artery-brachial vein autogenous fistula for hemodialysis: an alternative autogenous option for hemodialysis access. J Vasc Surg. 2005 Oct;42(4):806-10.

22 Greenberg JI, May S, Suliman A, Angle N. The brachial artery-brachial vein fistula: expanding the possibilities for autogenous fistulae. J Vasc Surg. 2008 Nov;48(5):1245-50.
23 Fila B, Lovčić V, Sonicki Z, Magaš S, SudarMagaš Z, Malovrh M. Vein diameter after intraoperative dilatation with vessel probes as a predictor of success of hemodialysis arteriovenous fistulas. Med Sci Monit. 2014 Feb;20: 191-8.

24 Varcoe RL, Teo AB, Pelletier MH, Yu Y, Yang JL, Crowe PJ, et al. An arteriovenous fistula model of intimal hyperplasia for evaluation of a nitinol U-Clip anastomosis. Eur J Vasc Endovasc Surg. 2012 Feb;43(2):224-31.

25 Masengu A, Maxwell AP, Hanko JB. Investigating clinical predictors of arteriovenous fistula functional patency in a European cohort. Clin Kidney J. 2016 Feb;9(1):142-7.

26 Hörer TM, Skoog P, Quell R, Nilsson KF, Larzon T, Souza DR. No-touch technique for radiocephalic arteriovenous fistula-surgical technique and preliminary results. J Vasc Access. 2016 Jan-Feb;17(1):6-12.

27 Wilson WE. Autologous Arteriovenous Fistulas: Direct Radiocephalic Anastomosis for Hemodialysis Access. In: Wilson SE, editor. Vascular Access: Principles and Practice. 5th ed. Philadelphia: Lippincott Williams \& Wilkins; 2010. pp. 86-92.

28 Davidson I, Gallieni M, Saxena R, Dolmatch B. A patient centered decision making dialysis access algorithm. J Vasc Access. 2007 AprJun;8(2):59-68.

29 Waheed D, Zarin M, Khan I, Ali A, Akbar S, Kamran H. Outcome of arteriovenous fistulae in patients with end stage renal disease. Gunma J Med Sci. 2010;8(2):176-80.

30 Hasson JE, Megerman J, Abbott WM. Suture technique and para-anastomotic compliance. J Vasc Surg. 1986 Apr;3(4):591-8.

31 De Marco Garcia LP, Davila-Santini LR, Feng Q, Calderin J, Krishnasastry KV, Panetta TF. Primary balloon angioplasty plus balloon angioplasty maturation to upgrade small-caliber veins $(<3 \mathrm{~mm})$ for arteriovenous fistulas. J Vasc Surg. 2010 Jul;52(1):139-44.

32 Veroux P, Giaquinta A, Tallarita T, Sinagra N, Virgilio C, Zerbo D, et al. Primary balloon angioplasty of small ( $\leq 2 \mathrm{~mm}$ ) cephalic veins improves primary patency of arteriovenous fistulae and decreases reintervention rates. J Vasc Surg. 2013 Jan;57(1):131-6.

33 Turmel-Rodrigues LA. Mechanical enhancement of AVF maturation. J Vasc Access. 2014 15(Suppl 7):S55-9. 